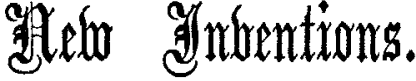

\section{IMPROVED ARTERY FORCEPS.}

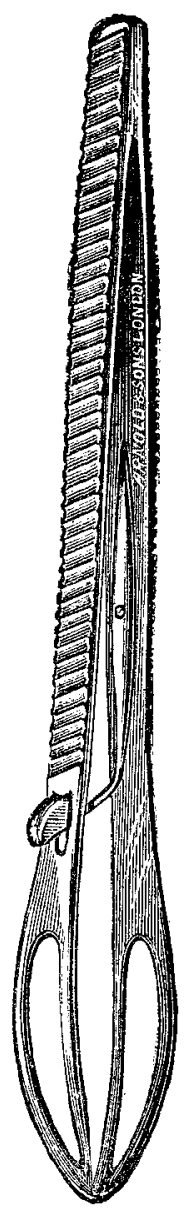

ONE defect of nearly every pair of artery forceps is the smoothness of the handles for quite half their length. In the operation of tying an artery it "is expedient that the assistant's finger and thamb holding the forceps should be as far from the wound as possible, so as not to be in the way and in the light ; but it is not particularly easy to hold on to the smooth end of the forceps, and if the grasp be on the roughened portion further down there is a considerable chance of loosing the catch. Also artery forceps make admirable tenacula for small tumours and the like; here, again, the further the pull the easier the work. So I have had the accompanying artery forceps made to my design by Messrs. Arnold and Son, having the sides roughened for about three-quarters of their lengtb, and so affording an excellent hold.

E. Mansel Sympson, M.D., Surgeon, Lincoln County Hospital.

\section{A SELF-LIGHTING GAS-BURNER.}

ALTHOUGH the principle upon which the working of this attractive device depends has long been known, yet it has not until now been successfully applied in practice to the automatic lighting of gas. So far back as 1823 Döbereiner observed that when a current of hydrogen impinged upon that peculiar variety of platinum known as platinum black, or spongy platinum, heat was developed until the intensity of it was such as to cause the platinum to glow and eventually to ignite the hydrogen. Döbereiner constructed a lamp which consisted essentially of a hydrogen generator (zinc and sulpharic acid being employed for this purpose), provided with a jet from which the generated hydrogen issued upon a small cage containing spongy platinum. The explanation of this peculiar phenomenon is simply that platinum has the power of absorbing or "occluding" bydrogen and other combustible gases as well as the oxygen of the air within its pores, and bringing them into such intimate contact that union results. In short, combustion ensues and the platinum glows. Perfectly clean and chemically pure platinum effects the same thing, but it does not appear so active and reliable as the spongy variety. Even the latter fails from some cause or other now and again. To Mr. Dake, however, of 20, High Holborn, W.C., belongs the credit, so far as we have experimented, of overcoming this uncertainty. How this has been achieved we do not know precisely, but we are told that the self-lighting burner bearing his name was the result of several years' study, and, we may add, his labours have been rewarded with apparent success judging from the satisfactory results we have obtained with the new self-lighting burner recently examined. Its construction is simple enough. An ordinary batswing burner, provided with a governor, has soldered on the side of it a small brass rod, on the top of which is a cap of black spongy material, presumably platinum. From the apex of this cap projects a thin platinum wire in the direction and on a plane with the base of the flame. On turning on the gas a current, which forms the blue part of the flame when ignited, impinges directly on the metallic spongy mass, with the result that it soon begins to glow, heating the platinum wire to a bright red heat, which then ignites the escaping gas, the whole action being completed in the tests we have made in less than eight seconds. The convenience of such a device hardly needs emphasising. It is no small advantage of the electric light that it can be turned on by merely "switching" and without resorting to the use of matches. The little platinum automatic igniting torch which Mr. Duke has perfected would seem now to offer the same advantages in gas lighting. It will prove most useful where light is wanted in emergency, as in the sick room, while it dispenses with keeping a small jet constantly burning the accidental extinction of which, as by a draught, may involve risks not only of coal-gas poisoning, but also of explosion. If it were possible to apply it this invention would obviously be a most valuable adjunct to gas fires.

\section{HARTMANN'S HYGIENIC TOWELETTES.}

THESE towelettes, also known as wood-wool diapers for ladies, have been for many years so favourably received that a detailed description is hardly necessary. The absorbent pad is very light and soft, closely resembling cotton wool, and is enclosed in coarse gauze, the ends of which are long, for the convenience of fastening. This material readily takes up fluids of the consistence usual in discharges, being comparatively free from the disagreeable tendency to become coated with them superficially. Towelettes which have served their purpose are burnt. They are of various qualities and prices, from a shilling per dozen upwards, the most substantial form being intended for use after accouchement. The mana. facturers have adapted their wood-wool to several other purposes of a similar nature, such as infants' napkins and sheets for use during accouchement. These last are in three sizes, the largest being thirty-two inches square; in addition to being soft, comfortable, and inexpensive they absorb the discharges completely and are burned after use, thereby reducing the chances of septic infection. The office of the company is at 26, Thavies-inn, Holborn-circus. Another of their appliances for ladies' use is a stocking suspender, which serves also as a support for the towelettes.

\section{A CABINET FOR PLASTERS AND DRESSINGS.}

MESSRs. FerRis AND Co. of Bristol have forwarded to us a wooden cabinet, about 18 in. long by 13 in. in height and $11 \mathrm{in}$. in breadth, which is divided into thirteen compartments, each of which contains one of their "ever-ready caddies." The caddy is an ingenious device for keeping in order plasters and other surgical dressings which the busy practitioner is constantly using. Each dressing is wound upon a hollow cylinder, which fixes upon a metal axis running through the middle of the caddy, the caddy itself being an obling tin box, and when required the dressing can be pulled from its reel and the quantity needed cat off. At the end of the caddy is a metal slide, on which is distinctly printed the name of the dressing contained in the box. The caddy is refilled by removing the label slide and taking out the metal axis, which is put through the new roll of dressing, fixed in position in the caddy, and the label slide replaced. The cabinet is a handsome piece of furniture and will be fonnd a useful addition to the fixtures either of the private surgery, or the public dispensary, or out-patient department.

\section{OZANITE SANITARY RINGS.}

THESE consist really of large wafers of vegetable parchment containing a definite quantity of pure permanganate of potassium, which, being crystalline, diffuses slowly out when the ring is floated on water. One advantage of such an arrangement is that the purity and strength of the permanganate is ensured. The ring is obviously convenient and useful for a variety of purposes, while it may be used with confidence for the delicate requirements of a gargle or as an application for cuts and wounds since the materials are quite pure and the paper free from injurious colouring substances. Meritorious as in many respects we concede this invention to be, we must enter a vigorous protest against the adoption of the name of a medical man in its title. "The Dr. Latham Ozanite Rings" is extremely objectionable, as our readers will agree, 